\title{
ENTRE A HISTÓRIA, A MEMÓRIA E O NACIONALISMO (?): AS HISTÓRIAS EM QUADRINHOS DO MUSEU DE AUSCHWITZ-BIRKENAU
}

\author{
Victor Callari ${ }^{1}$
}

\begin{abstract}
RESUMO: A série "Episodes From Auschwitz" publicada pela editora polonesa K \& L Press em parceira com o Auschwitz-Birkenau State Museum consiste em uma série de quatro histórias em quadrinhos. A obra contou com a consulta e participação de historiadores e sobreviventes de Auschwitz durante sua confecção, e por esse motivo, reivindicou o status de "primeira HQ histórica" sobre Auschwitz. Esta pesquisa verifica os possíveis significados e limitações que a noção de "HQ histórica", tal qual expressa pela série, pode carregar, a partir de uma análise das diferentes concepções de história que se manifestam na obra e das tensões entre os campos da história, da memória e do testemunho, elementos estruturantes das representações do passado construídos "na" e "pela" obra. O aporte teórico utilizado consiste na articulação da noção de representação, tal qual expressa pelo historiador francês Roger Chartier e a noção de documento-monumento do historiador Jacques Le Goff, com as reflexões acerca da Memória e do Testemunho presentes em autores como François Hartog e Paul Ricoeur.
\end{abstract}

PALAVRAS-CHAVE: Histórias em Quadrinhos; Segunda Guerra Mundial; Memória; Historiografia.

\section{BETWEEN HISTORY, MEMORY AND NATIONALISM (?): THE AUSCHWITZ- BIRKENAU MUSEUM'S COMIC BOOKS}

\begin{abstract}
The "Episodes From Auschwitz" series published by the Polish publisher K \& L Press in partnership with the Auschwitz-Birkenau State Museum consists of a series of four comic books. The work counted on the consultation and participation of historians and survivors of Auschwitz during its preparation, and for that reason, claimed the status of "first historical HQ" on Auschwitz. This research verifies the possible meanings and limitations that the notion of "historical HQ", as expressed by the series, can carry, from an analysis of the different conceptions of history on the piece and the tensions between the fields of history, memory and testimony, structuring elements of the representations of the past constructed "in" and "by" the piece. The theoretical contribution consists in the articulation of the notion of representation, as expressed by the French historian Roger Chartier and the notion of document-monument of the historian Jacques Le Goff, with the reflections on Memory and Witness present in authors such as François Hartog and Paul Ricoeur.
\end{abstract}

KEYWORDS: Comic Book; Second World War; Memory; Historiography.

\footnotetext{
${ }^{1}$ Doutorando em História Social pela Universidade de São Paulo (USP). Mestre em História e Historiografia pela Universidade Federal de São Paulo (Unifesp). Autor do livro "Guerra Civil: super-heróis, terrorismo e contraterrorismo nas histórias em quadrinhos", publicado pela editora Criativo em 2016.
} 


\title{
ENTRE LA HISTORIA, LA MEMORIA Y EL NACIONALISMO (?): LAS HISTORIAS EN CUADRIÑOS DEL MUSEO DE AUSCHWITZ-BIRKENAU
}

\begin{abstract}
RESUMEN: La serie "Episode From Auschwitz" publicada por la editorial polaca K \& L Press en asociación con el Auschwitz-Birkenau State Museum consta de una serie de cuatro historias en cuadriños. La obra contó con la consulta y participación de historiadores y sobrevivientes de Auschwitz durante su confección, y por ese motivo, reivindicó el estatus de "primera HQ histórica" sobre Auschwitz. Esta investigación verifica los posibles significados y limitaciones que la noción de "HQ histórica", tal cual expresa por la serie, puede llevar, a partir de un análisis de las diferentes concepciones de historia que se manifiestan en la obra y las tensiones entre los campos de la historia, de la memoria y del testimonio, elementos estructurantes de las representaciones del pasado construidos "en la" y "por la" obra. El aporte teórico utilizado consiste en la articulación de la noción de representación, tal como expresa el historiador francés Roger Chartier y la noción de documento-monumento del historiador Jacques Le Goff, con las reflexiones acerca de la memoria y el testimonio presentes en autores como François Hartog y Paul Ricoeur.
\end{abstract}

PAlABRAS CLAVE: Historias en cuadriños; II Guerra Mundial; memoria; Historiografía.

Entre os anos de 2009 e 2013 a editora K\&L Press, em parceria com o Auschwitz Birkenau State Museum, produziu e publicou uma série de quatro histórias em quadrinhos intitulada Episodes From Auschwitz. Ainda que a série não apresente elementos estéticos ou diferentes camadas de leitura em seu enredo permitindo-a figurar ao lado de outras narrativas consagradas sobre o Holocausto, como a premiada HQ "Maus: a história de um sobrevivente", de Art Spiegelman, algumas questões que ela suscita, como a elaboração de representações do passado por meio de histórias em quadrinhos, seu diálogo com os campos da memória e do testemunho, a própria percepção do que seria a História e o caráter pedagógico com que a série é apresentada, são o suficiente para suscitar reflexões acerca de sua fabricação, seu conteúdo e suas representações. Utilizamos a noção de representação tal qual formulada pelo historiador francês Roger Chartier.

As percepções do social não são, de forma alguma, discursos neutros: produzem estratégias e práticas (sociais, escolares, políticas) que tendem a impor uma autoridade à custa de outros por ela menosprezados, a legitimar um projeto reformador ou a justificar para os próprios indivíduos suas escolhas e condutas. Por isso esta investigação sobre as representações supõe-nas como estando sempre colocadas num campo de concorrências e de competições cujos desafios se enunciam em termos de poder e de dominação. As lutas de representações têm tanta importância como as lutas econômicas para compreender os mecanismos pelos quais um grupo impõe, 
Entre a história, a memória e o nacionalismo (?): as histórias em quadrinhos do Museu de Auschwitz-Birkenau

ou tenta impor, a sua concepção do mundo social, os valores que são os seus, e o seu domínio (CHARTIER, 2002, p.17).

A série tem suas histórias centradas na trajetória de personagens poloneses e judeus e suas experiências durante o período em que estiveram presos no campo de concentração de Auschwitz II-Birkenau ${ }^{2}$. Os quatro volumes da série foram escritos pelo roteirista Michal Galek, e cada um dos volumes contou com a participação de um desenhista diferente e responsável pela $\operatorname{arte}^{3}$.

Figura 1: Capa do primeiro volume da série

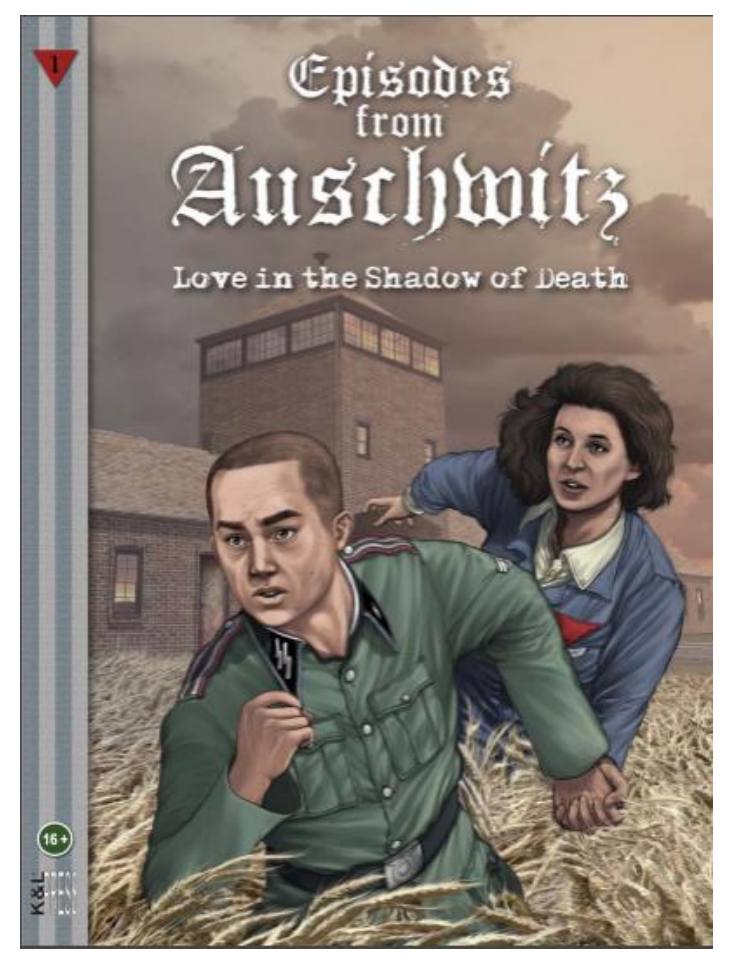

Fonte: GALEK, Michal; NOWAKOWSKI, Marcin.

Episodes From Auschwitz: Love in the Shadow of death. K\&L Press, 2009.

\footnotetext{
${ }^{2} \mathrm{O}$ campo de concentração de Auschwitz-Birkenau foi um dos três mais importantes campos de concentração do complexo de Auschwitz, ao lado de Auschwitz I e Auschwitz III - Monowitz. O complexo foi construído em 1940, na cidade polonesa de Oswiecim.

${ }^{3}$ Todos os artistas fazem parte de um estúdio de design e artes gráficas chamado Part Studio, e em suas apresentações destacam a experiência com trabalhos visuais para o mercado de comunicação e histórias em quadrinhos.
} 
Fronteiras: Revista de História

Entre a história, a memória e o nacionalismo (?): as histórias em quadrinhos do Museu de Auschwitz-Birkenau Victor Callari

Figura 2: Capa do segundo volume da série

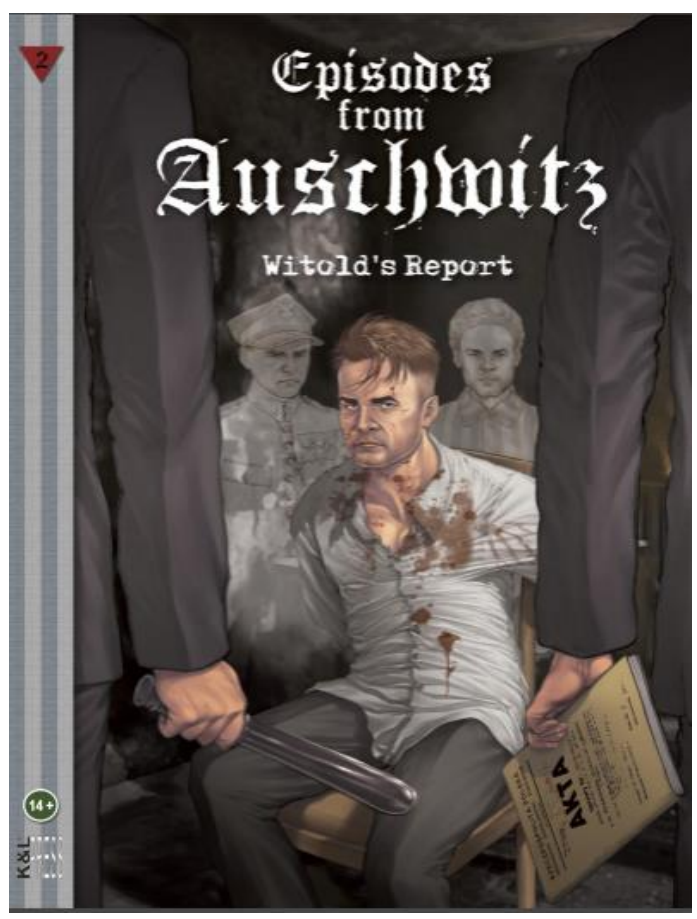

Fonte: GALEK, Michal; KLIMEK, Arkadiusz.

Episodes From Auschwitz: Witold's Report. K\&L Press, 2009.

Figura 3: Capa do terceiro volume da série

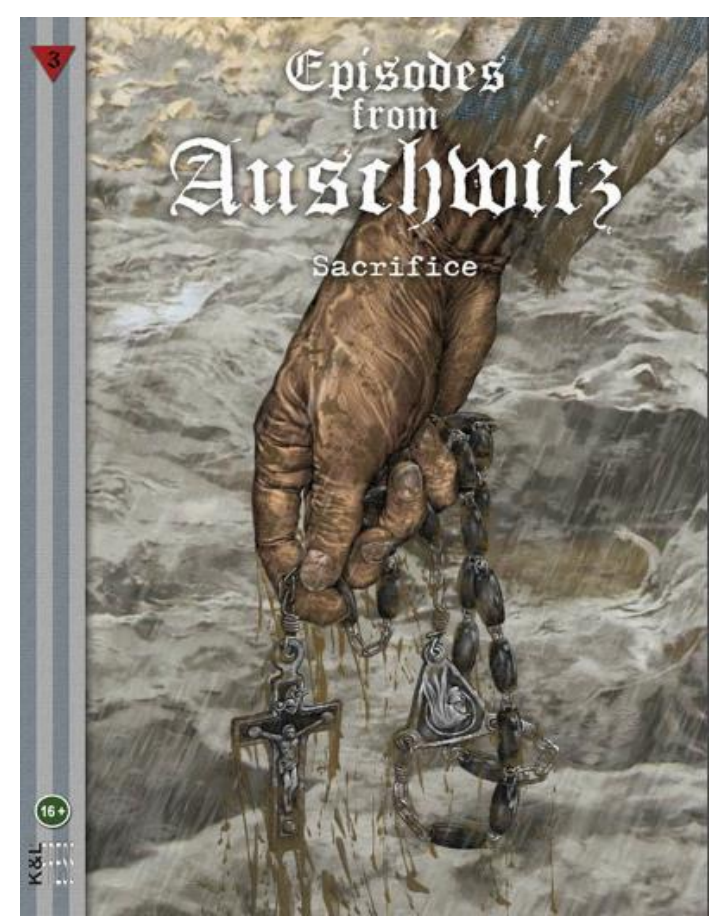

Fonte: GALEK, Michal; POLLER, Lukasz.

Episodes From Auschwitz: Sacrifice. K\&L Press, 2013.

Fronteiras: Revista de História | Dourados, MS | v. 20 | n. 36 | p. 38-51| Jul. / Dez. 2018 
Entre a história, a memória e o nacionalismo (?): as histórias em quadrinhos do Museu de Auschwitz-Birkenau Victor Callari

Figura 4: Capa do quarto volume da série

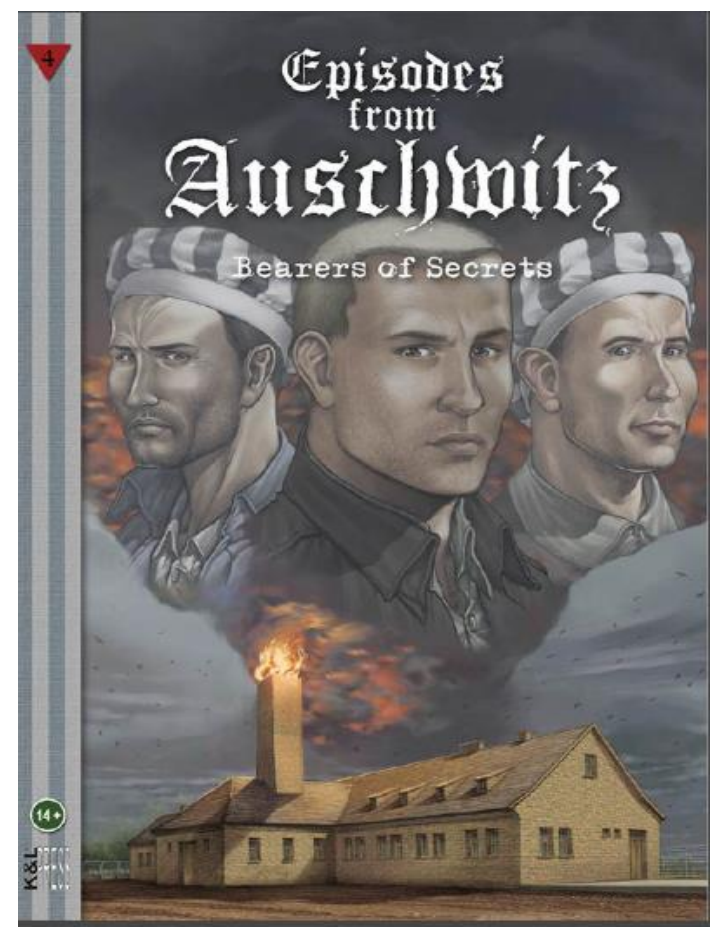

Fonte: GALEK, Michal; PYTERAF, Michal.

Episodes From Auschwitz: Bearers of Secrets. K\&L Press, 2013.

O primeiro volume, "Love in the shadow of death", desenhado por Marcin Nowakowski, conta a história da malsucedida tentativa de fuga do campo, ocorrida em 1944, do casal Edward Galinski, um prisioneiro polonês, e Mala Zimetbaum, uma prisioneira judia. O segundo volume, intitulado de "Witold's report", foi desenhado por Arkadiusz Klimek e narra a história do soldado da resistência polonesa Witold Pilecki que se voluntariou para ir a Auschwitz com o objetivo de colher informações sobre o campo e escapou. O terceiro volume, "Sacrifice", foi desenhado pelo artista Lukasz Poller e destacou a trajetória do padre católico Kolbe, que se sacrificou no lugar do prisioneiro 5659, Franciszek Gajowniczek, escolhido junto com outros nove presos para ser morto como represália à fuga de um prisioneiro em 1941. O último volume, "Bearers of secrets, desenhado por Michal Pyteraf, cria o personagem Joshua como uma forma de representar os responsáveis pela revolta dos sonderkommandos, em $1944^{4}$.

\footnotetext{
${ }^{4}$ Os sonderkommandos consistiam em um destacamento especial de prisioneiros que trabalhavam na área de extermínio dentro do campo de Auschwitz II realizando atividades como a limpeza das câmaras de gás e o enterro de corpos de outros prisioneiros. No verão de 1944 chegaram mais de 400 mil prisioneiros no campo e o grupo de sonderkommandos foi ampliado. Contudo, com a redução realizada no outono do mesmo ano, os
} 
Entre a história, a memória e o nacionalismo (?): as histórias em quadrinhos do Museu de Auschwitz-Birkenau Victor Callari

A obra apresenta elementos visuais e textuais que compõem aquilo que Roger Chartier definiu como a materialidade dos impressos (CHARTIER, 2010, p.8) e que, segundo o autor, é capaz de produzir outros sentidos à prática leitora. As revistas foram produzidas em um tamanho considerado padrão, de $20 \mathrm{~cm}$ por $30 \mathrm{~cm}$, coloridas e possuíam 40 páginas cada. Todos os volumes possuem uma seção de abertura de duas páginas, divididas entre texto e desenhos cujo objetivo é inserir o enredo da história no contexto mais amplo da Segunda Guerra Mundial servindo, assim, como uma apresentação do tema. Esse texto de abertura é sucedido por uma página de introdução com informações sobre o campo de concentração de Auschwitz (figura 1).

Figura 5: Página de introdução

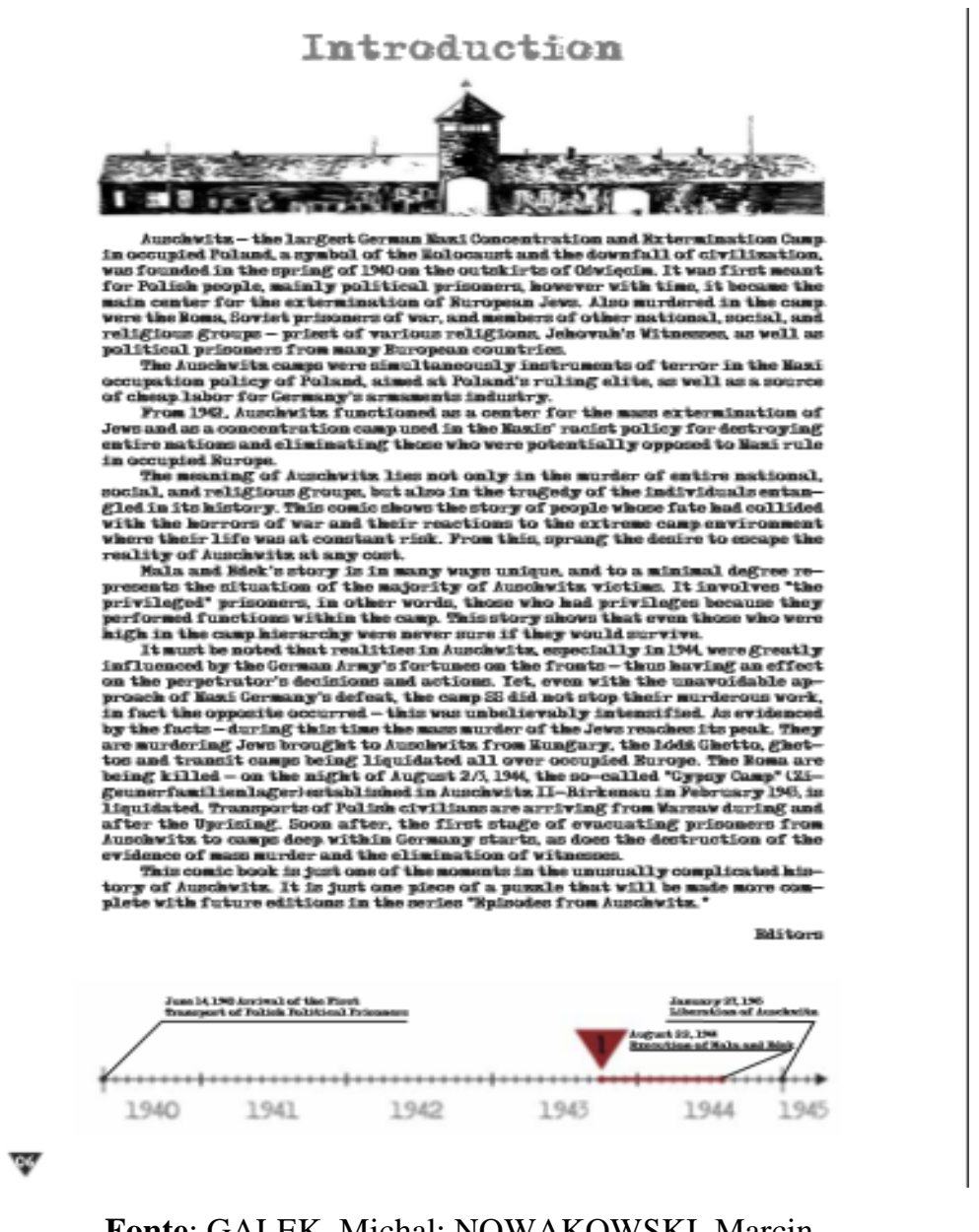

Fonte: GALEK, Michal; NOWAKOWSKI, Marcin.

Episodes From Auschwitz: Love in the Shadow of death. K\&L Press, 2009, p. 7.

prisioneiros passaram a temer pelas suas vidas, organizando uma revolta em 7 de outubro. Durante a revolta alguns soldados da SS foram mortos e parte do crematório IV destruída. Com a aproximação dos Soviéticos, os soldados alemães destruíram os outros crematórios junto com outras evidências dos crimes cometidos. 
Entre a história, a memória e o nacionalismo (?): as histórias em quadrinhos do Museu de Auschwitz-Birkenau

Na página introdutória, na parte superior, uma imagem representa a entrada do campo de Birkenau, enquanto que na parte inferior, é possível identificar uma "linha do tempo" com marcos na chegada dos prisioneiros ao campo, ainda em 1940, e a libertação em 27 de janeiro de 1945, destacando a execução do casal retratado na história em 22 de agosto de 1944. O olhar da sociologia dos textos acerca das duas primeiras seções que procuram localizar o leitor historicamente, inserindo a narrativa dentro do contexto mais amplo da Segunda Guerra Mundial a partir da utilização de textos com vocabulário simples e informações pontuais, interrompidos por ilustrações, permite enxergar também uma representação do próprio público leitor feita pelos artistas e editores. A partir dos elementos mencionados, não é possível inferir que a obra é destinada ao público especializado na Segunda Guerra Mundial ou nos campos de concentração, tampouco aparenta ser destinada a um público habituado a leituras longas e exigentes.

Outro elemento presente em todas as revistas é a seção intitulada "afterword", assinada nos três primeiros volumes pelo historiador e funcionário do museu, Adam $\mathrm{Cyra}^{5}$, e no último volume pelos "editores". Essa seção consiste em um breve comentário acerca dos personagens retratados e das fontes consultadas para a elaboração da narrativa, assim como evidencia a "estranha" relação da obra com o Auschwitz-Birkenau State Museum.

Apesar de serem comercializadas dentro do próprio museu, as HQs da série não são apresentadas como parte de sua proposta educativa sobre a história do campo de concentração, dos prisioneiros e do Holocausto. Formalmente, apenas a série em quadrinhos "A fuga", produzida em parceria com a Fundação Anne Frank, é mencionada na seção de educação disponível no site ${ }^{6}$. Entretanto, o que mais se destaca são as diferentes concepções de história que permeiam a narrativa da série Episodes From Auschwitiz, analisadas aqui a partir de elementos relacionados a ideia de ficção e fato, e trauma e narrativa. A obra dialoga com algumas das condições e características do novo regime de historicidade, denominado por François Hartog como "presentismo". Segundo Hartog, o regime de historicidade consiste em "uma ferramenta heurística, ajudando a apreender, não o tempo, todos os tempos, ou a totalidade do tempo, mas principalmente momentos de crise do tempo" (HARTOG, 2017, p. 37), essa noção é formulada em nossa contemporaneidade e capaz de permitir ao historiador

\footnotetext{
${ }^{5}$ Nos dois últimos volumes da série a seção foi assinada pelos editores.

${ }^{6}$ Sobre ações educativas no âmbito de museus, ver: MUSEUS, Libraries and Archives Council. Educação em museus. São Paulo: Edusp/Fundação Vitae, 2005. Vol.3. Série Museologia - roteiros práticos.; BARBOSA, Ana Mae. Ensino da arte: memória e história. São Paulo: Perspectiva, 2008, v.1. 353p.
} 
Entre a história, a memória e o nacionalismo (?): as histórias em quadrinhos do Museu de Auschwitz-Birkenau Victor Callari

questionar as relações que os homens mantêm com o tempo. Hartog ainda afirma que "um regime de historicidade nunca foi uma entidade metafísica, caída do céu e de alcance universal. É apenas a expressão de uma ordem dominante do tempo. Tramado por diferentes regimes de temporalidade, ele é, concluindo, uma maneira de traduzir e de ordenar experiências do tempo - modos de articular passado, presente e futuro - e de dar-lhes sentido (HARTOG, 2017, p.139). Hartog destaca como uma das evidências dessa nova mudança a ascensão da onda memorial. Para o historiador francês, além da aceleração do tempo e do avanço da memória em detrimento da história, o papel dos testemunhos na sociedade contemporânea, a proliferação de obras literárias baseadas na memória e a onda patrimonial, entre outros exemplos, referendam essa nova configuração.

Destacar esses elementos torna-se importante na medida em que realça as características do contexto histórico que "autoriza" a construção das representações do passado presentes na série, notadamente marcada por uma valorização da memória e do testemunho como discursos acerca desse mesmo passado enquanto busca na história uma ferramenta de validação de seus discursos.

Além de um diálogo aberto com as condições do novo regime de historicidade, a série dialoga com algumas das principais tendências desenvolvidas pela historiografia no decurso do século XX. Ao optarem por narrar a trajetória de indivíduos presos no campo de concentração e extermínio de Auschwitz, os responsáveis pela série rejeitaram modelos oriundos do século XIX, cujas narrativas voltavam-se para a trajetória de pessoas importantes, como reis, governantes e heróis, de forma a fornecer as bases que sustentariam os Estados Nacionais. Os produtores voltaram-se para personagens pouco ou nada conhecidos, cujas histórias estariam restritas apenas a uma pequena parcela de pesquisadores muito especializada na história do campo de concentração e seus prisioneiros. A preocupação com esses agentes históricos esquecidos ganhou forma e destaque na historiografia a partir da publicação, em 1966, do artigo "History From Below", escrito pelo historiador inglês Edward Palmer Thompson (THOMPSON, 1966). Desde então sua concepção de que a história deveria valorizar os grupos "vencidos" e "silenciados" adquiriu enorme prestígio entre historiadores de todo o mundo, independente dos recortes temáticos e temporais de suas pesquisas. $\mathrm{Na}$ Inglaterra destacaram-se pesquisas relacionadas aos movimentos operários, na França buscouse encontrar os modos de vida dos camponeses no final da Idade Média, na Itália destacou-se 
Entre a história, a memória e o nacionalismo (?): as histórias em quadrinhos do Museu de Auschwitz-Birkenau

a trajetória de um moleiro, no Brasil as experiências dos escravos entre tantos outros grupos e temas.

Outra tendência historiográfica que parece permear a série, é a abordagem conhecida por Micro-História ${ }^{7}$. Essa abordagem consiste em um jogo de escalas por parte do historiador, de forma a identificar aspectos importantes que poderiam passar despercebidos se analisados sob outras perspectivas, como elementos do cotidiano ou estratégias silenciosas de resistência.

Ainda que de maneira inconsciente, ao optarem por restringir o enredo da série ao campo de concentração e extermínio de Auschwitz e seus prisioneiros, os artistas e produtores operaram de maneira similar a como operam os historiadores adeptos da Micro-História, preocupados com trajetórias individuais e não com categorias como prisioneiros e perpetradores. Sendo assim, em um primeiro momento a série parece dialogar com algumas das tendências mais modernas da historiografia do século XX, enquanto se afastava de tendências historiográficas ditas estruturalistas, cuja preocupação com as estruturas econômicas ou mentais resultaram em um "desaparecimento" dos sujeitos da História. A série parece oferecer um rosto aos agentes históricos, preocupando-se com suas ações individuais, seus medos e anseios, assim como com a possibilidade de compreensão de todo um contexto histórico mais amplo por meio do exame de trajetórias individuas, operando em um jogo de escalas entre o micro e macro. Esse processo resulta em uma humanização do passado e em uma maior aproximação com o público leitor.

Entretanto, embora faça escolhas que a aproximaram de algumas das tendências mais importantes e inovadoras da historiografia do século XX, a série não foi capaz de se filiar a essa mesa historiografia. Sua concepção de História aparece como um paradoxo às escolhas apresentadas até então, na medida em que a história é tratada como um dado pronto e acabado, e seu papel aparenta ser o de narrar, teleologicamente, o passado tal qual ele realmente teria acontecido. Na série as tendências mais modernas da historiografia são suplantadas pelo predomínio de uma concepção historiográfica forjada no século XIX, resultando em uma concepção de história e passado com características específicas e particular.

Verifiquemos o release enviado a imprensa e disponível no site:

\footnotetext{
${ }^{7}$ A Micro-História adquiriu enorme prestígio entre os historiadores a partir da publicação da obra "O queijo e os vermes" (1976), do historiador italiano Carlo Guinzburg, em que ele procura entender as estruturas de funcionamento do moleiro Menocchio a partir de documentos inquisitoriais.
} 
Entre a história, a memória e o nacionalismo (?): as histórias em quadrinhos do Museu de Auschwitz-Birkenau Victor Callari

PARA A IMPRENSA: "Episodes from Auschwitz" - A primeira HQ histórica sobre Auschwitz. Apresentamos ao leitor o primeiro quadrinho histórico sobre Auschwitz baseado em fontes históricas confiáveis. Retornamos ao assunto de Auschwitz usando uma linguagem diferente e tendo em mente o leitor contemporâneo. A história de Auschwitz é apresentada mostrando o destino de pessoas reais, mostrando como elas realmente eram, seus altos e baixos, esperanças e dúvidas durante o pesadelo de Auschwitz. (...). A série de quadrinhos "Episodes from Auschwitz" foi criada em cooperação com historiadores especializados em campos de concentração e extermínio, assuntos militares e Segunda Guerra Mundial. O trabalho no quadrinho é acompanhado por consultas aprofundadas com sobreviventes, especialmente os ex-prisioneiros de Auschwitz.

Depois de inúmeras tentativas de apresentar a história do Holocausto em forma de quadrinhos, como por exemplo a obra "Maus", de Spiegelman, é hora de um livro de quadrinhos histórico sobre Auschwitz, em que a história seja apresentada sem distorções ideológicas e estereótipos nocivos. A história é mostrada honestamente e de forma interessante. $90 \%$ dos eventos nos quadrinhos são historicamente precisos, com base no testemunho de exprisioneiros, $10 \%$ dos eventos são historicamente prováveis - situações e eventos, que ocorreram em Auschwitz e foram descritos em memórias, bem como testemunhados por algumas pessoas retratadas nos quadrinhos. Um quadrinho histórico direto, em uma forma gráfica atraente, escrito de forma animada, oferece a oportunidade de perceber melhor os trágicos eventos e, portanto, obter um conhecimento mais direto da história ${ }^{8}$.

Primeiramente, o comunicado apresenta as representações da série como uma construção produzida a partir de fontes históricas "confiáveis". Poderíamos então presumir que existem fontes confiáveis e fontes não confiáveis? O que os historiadores devem fazer com as fontes não confiáveis? Descartá-las? Tais questões foram centrais nas críticas que marcaram a ruptura dos historiadores da Escola dos Annales com seus antecessores do século XIX, que acreditavam que o papel do historiador residia em identificar e separar os

\footnotetext{
${ }^{8}$ Tradução livre: FOR PRESS: "Episodes from Auschwitz"—-the first historical comic book about Auschwitz. We present the Reader with the first historical comic book about Auschwitz based on reliable historical sources. We return to the subject of Auschwitz using a different form and bearing in mind the contemporary Reader. The history of Auschwitz is presented by showing the fate of real people, showing them as they really were, their ups and downs, hopes and doubts in the nightmarish depravity of Auschwitz. (...). The series of comics "Episodes from Auschwitz" is created in cooperation with historians specializing in concentration and extermination camps, military matters, and World War II. Work on the comic is accompanied by in-depth consultations with survivors, especially former prisoners of Auschwitz. After numerous attempts to present the history of the Holocaust in comic book form-for example Spiegelman's literary "Maus" - it is time for a historical comic book about Auschwitz, in which history is presented without ideological skew and harmful stereotypes. History is shown here honestly and in an interesting way. $90 \%$ of the events in the comics are historically accurate, based on testimony of former prisoners, $10 \%$ of the events are historically likely - situations and events, which had taken place in Auschwitz and were described in memoirs, as well as witnessed sometimes by the people presented in the comic books. A straightforward historical comic in an attractive graphical form, written in a lively way, offers the opportunity to better perceive the tragic events, and therefore to gain a more direct knowledge of the history. Disponível em < http://episodesfromauschwitz.pl/en/prasa.html >, acessado em $25 / 02 / 2018$
} 
Entre a história, a memória e o nacionalismo (?): as histórias em quadrinhos do Museu de Auschwitz-Birkenau Victor Callari

documentos falsos dos documentos verdadeiros, procedendo com o estudo apenas a partir de fontes confiáveis. Sobre isso Jacques Le Goff fez considerações:

A primeira é que um documento "falso" também é um documento histórico e que pode ser um testemunho precioso da época em que foi forjado e do período durante o qual foi considerado autêntico e, como tal, utilizado. A segunda é que um documento, nomeadamente um texto, pode sofrer, ao longo das épocas, manipulações aparentemente científicas que de fato obliteraram o original (LE GOFF, 1996, p. 91).

A chamada "revolução francesa da historiografia" (BURKE, 1997) não teve como consequência apenas a ampliação da definição do que seriam as fontes históricas, mas também implicou em uma nova forma de lidar com essas fontes, portanto, ao afirmar que as HQs utilizam de fontes históricas "confiáveis", os produtores se aproximam de uma concepção histórica datada e superada na historiografia. No decorrer do século XX os documentos e fontes passaram a ser percebidos como detentores de historicidade própria e específica, mantendo um diálogo não apenas com o momento que os produziu, mas também com sua trajetória até chegar às mãos dos homens no presente. Segundo Le Goff:

O documento não é inócuo. É, antes de mais nada, o resultado de uma montagem, consciente ou inconsciente, das sociedades que o produziram, mas também das épocas sucessivas durantes as quais continuou a viver, talvez esquecido, durante as quais continuou a ser manipulado, ainda que pelo silêncio. $\mathrm{O}$ documento é uma coisa que fica, que dura, e o testemunho, o ensinamento (para evocar a etimologia) que ele traz devem ser em primeiro lugar analisados, desmitificando-lhe o seu significado aparente. $\mathrm{O}$ documento é monumento. Resulta do esforço das sociedades históricas para impor ao futuro - voluntária ou involuntariamente - determinada imagem de si próprias. No limite, não existe um documento verdade. Todo documento é mentira. Cabe ao historiador não fazer o papel de ingênuo (LE GOFF, 1996, p. 538).

No decorrer do texto, o comunicado afirma ainda que a série apresenta "o destino de pessoas reais, mostrando-lhes como elas realmente eram, seus altos e baixos, esperanças e dúvidas". A noção de verdade parece se aproximar da ideia de fato histórico em oposição à ideia de ficção, presente em outras formas de narrativa.

No campo dos estudos históricos, as Histórias em Quadrinhos não são compreendidas pela aproximação de seu enredo com o mundo real, como a noção de HQ histórica pode erroneamente nos fazer presumir. As HQs são percebidas como práticas culturais que se 
Entre a história, a memória e o nacionalismo (?): as histórias em quadrinhos do Museu de Auschwitz-Birkenau Victor Callari

relacionam com a sociedade que as produziu por uma complexa teia de relações que devem ser desvendadas pelo historiador. Suas representações devem ser compreendidas, entre outras coisas, pelo diálogo com o conjunto de representações de sua época, destacando suas rupturas, continuidades, suas filiações políticas ou ideológicas, pelos interesses comerciais que determinam sua materialidade e circulação e pelas práticas leitoras que as cercam. A compreensão das histórias em quadrinhos como um espelho, ou reflexo do mundo social, atribui um caráter passivo ao objeto, suas representações e seus leitores, retirando o caráter dialético em que a obra atua como construtora desse próprio mundo.

No caso de HQs que se colocam como testemunhos do passado, como a já mencionada obra "Maus", ou a série "Episodes from Auschwitiz" se propõe, os historiadores devem considerar não apenas o teor daquilo que testemunham, mas também como representam esse testemunho, desvendando essas escolhas e apontando para as relações com o mundo social em que os artistas responsáveis pela obra estavam inseridos. Nesse sentido, a preocupação da obra em reafirmar a existência de "pessoas reais", as constantes referências às fontes confiáveis, à consulta e participação de historiadores especialistas no tema e de sobreviventes que atuam como testemunhas oculares dos eventos retratados, serve exclusivamente para atestar as representações elaboradas e, portanto, nos diz muito mais sobre a presença da obra na primeira década do século XXI e sua preocupação com a aceitação e credibilidade do mercado consumidor, sua preocupação com a preservação da memória do Holocausto na medida em que um número cada vez menor de sobreviventes está vivo para prestar testemunho ou refutar teorias negacionistas, do que propriamente sobre o enredo e as pessoas que estiveram em Auschwitz durante a Segunda Guerra Mundial.

A oposição entre ficção e fato, quando sinônimo da oposição entre ficção e verdade, pode conduzir os pesquisadores a buscarem nas fontes apenas os elementos que atestariam a veracidade de suas representações, levando a ficção a ser entendida como uma espécie de falseamento da realidade. Essa abordagem desconsidera as contribuições da historiografia e empobrece a multiplicidade de questões e diálogos presentes entre a obra e seu contexto social de produção.

A aproximação da série com uma concepção de História forjada no século XIX também pode ser observada na autodenominação de que ela seria a "primeira HQ histórica sobre Auschwitz". A noção de "historical comic book" apresentada pelos produtores da série silencia uma questão importante acerca da obra e enseja confusões, pois insere em uma 
Entre a história, a memória e o nacionalismo (?): as histórias em quadrinhos do Museu de Auschwitz-Birkenau

mesma categoria a história, a arte e a memória, como discursos do passado. Ainda que as três elaborem representações sobre o passado, o fazem sob premissas e preocupações distintas.

No que diz respeito aos discursos elaborados pela memória em relação ao passado, é importante destacar sua construção pelo tempo presente e, nesse sentido, apresenta proximidades com as condições de elaboração do discurso historiográfico. Entretanto, o discurso produzido pela memória pode, muitas vezes, se adaptar às necessidades da fala, aos diferentes contextos em que a memória é chamada a prestar testemunho. Segundo Paul Ricoeur:

De fato, o que o esquecimento desperta nessa encruzilhada é a própria aporia que está na fonte do caráter problemático da representação do passado, a saber, a falta de confiabilidade da memória; o esquecimento é o desafio por excelência oposto à ambição de confiabilidade da memória. Ora, a confiabilidade da lembrança procede do enigma constitutivo de toda a problemática da memória, a saber, a dialética de presença e de ausência no amago da representação do passado, ao que se acrescenta o sentimento de distância próprio à lembrança, diferentemente da ausência simples da imagem, quer esta sirva para descrever ou simular (RICOEUR, 2007, p. 425).

As ausências destacadas por Ricoeur, inerentes aos discursos da memória, não podem ser percebidas senão por aqueles que têm "domínio" sobre o passado e o repertório necessário para reconhecer suas omissões, no entanto, nos últimos anos, as representações do passado elaboradas pela memória não cessam de vencer e se fortalecem pela autoridade testemunhal. Segundo Hartog:

Em nossas sociedades, a ascensão da memória ao longo dos anos 1980, foi um forte indício desses deslocamentos. À Clio sucedeu sua mãe, Mnemosine: Memória, a mãe das musas. A "vaga memorialista" pouco a pouco invadiu, recobriu o terreno da história. Ao menos foi assim que se buscou dar conta do que estava acontecendo: passa-se da história à memória, pois a memória transforma a história, antes que a história busque recuperar o controle, apresentando-se como história da memória (HARTOG, 2017, p. 26).

As passagens acima, tanto de Ricoeur quanto de Hartog, reforçam a necessidade de uma reflexão histórica acerca da memória e dos diferentes veículos pelos quais ela se manifesta, seja por meio de testemunhos, entrevistas, documentários, ou histórias em quadrinhos. Em Episodes From Auschwitz estamos diante de uma série que reforça a 
autoridade de suas representações sobre o passado ao evocar a presença de historiadores e testemunhas oculares, dirimindo o caráter artístico das representações presentes na HQ e revestindo-as de uma "autoridade" historiográfica.

\section{REFERÊNCIAS}

BURKE, Peter. A escola dos Annales (1929-1989): a revolução francesa da historiografia. São Paulo: Editora Unesp, 1997.

CHARTIER, Roger. Escutar os mortos com os olhos. Estudos Avançados (São Paulo), vol.24, $\mathrm{n}^{\circ} 69,2010$.

CHARTIER, Roger. A História Cultural: entre práticas e representações. Portugal: Difel, 2002.

GINZBURG, Carlo. Mitos, Emblemas e Sinais: morfologia e história. São Paulo: Companhia das Letras, 1989.

HARTOG, François. Crer em História. Belo Horizonte: Autêntica, 2017.

LE GOFF, Jacques. História e memória. Campinas: Editora UNICAMP, 1996.

RICOEUR, Paul. A memória, a história, o esquecimento. Campinas: SP, Editora da Unicamp, 2007.

THOMPSON, Edward Palmer. History from Below. Times Literary Supplement, 7 April 1966.

Recebido em: 15/12/2018

Aprovado em: 21/01/2019 